\title{
BATALLAS OBRERAS EN CONTEXTOS DE RADICALIZACIÓN SOCIAL Y POLÍTICA EN LA AGROINDUSTRIA (GRAN ROSARIO, 1969- 1972)
}

\author{
WORKERS' STRUGGLE IN CONTEXTS OF SOCIAL AND POLITICAL \\ RADICALIZATION IN THE AGROINDUSTRY (GRAN ROSARIO, 1969-1972)
}

\author{
SILVIA SIMONASSI (ISHIR / UNR) \\ Investigaciones Socio-Históricas Regionales \\ Universidad Nacional de Rosario \\ silviasimonassi@yahoo.com.ar
}

\section{VERÓNICA VOGELMANN (ISHIR-CONICET / UNR)}

Investigaciones Socio-Históricas Regionales

Consejo Nacional de Investigaciones Científicas y Técnicas

Universidad Nacional de Rosario

veronicavogelmann@gmail.com

\section{Resumen:}

Este artículo se propone analizar las batallas obreras acontecidas en la industria de la alimentación en el Gran Rosario luego del "Cordobazo" (mayo de 1969) y de los "Rosariazos" (mayo y setiembre de 1969). Dichas luchas fueron escasamente exploradas por la historiografía hasta el momento desde la perspectiva propuesta. Se articulan transformaciones estructurales, luchas y organización en una escala regional/local sin perder de vista las dinámicas nacionales. Asimismo, se develan los límites y contradicciones del proceso de radicalización social y política en el marco de luchas defensivas, por la conservación de fuentes de trabajo frente a suspensiones, cesantías y cierres. Se utilizan fuentes diversas: entrevistas, prensa periódica, de organizaciones sindicales y políticas, y documentos de servicios de inteligencia.

\section{Palabras clave:}

Luchas obreras - reconversión productiva - industria de la alimentación - radicalización social y política - Gran Rosario

\begin{abstract}
:
This article intends to analyze the workers' struggles in the food industry that took place in the Gran Rosario after the "Cordobazo" (May 1969) and the "Rosariazos" (May and September 1969). Such struggles have been barely explored by historiography from the proposed perspective until now. Structural transformations, struggle and organization are articulated on a regional / local scale without losing sight of national dynamics. Moreover, it reveals limits and contradictions of the social and political radicalization process within the framework of defensive struggles. The latter were done for the conservation of workplaces in the face of suspensions, layoffs and closures. Various sources are used: periodic press, publications from trade unions and political organizations, and intelligence services' documents.
\end{abstract}

\section{Keywords:}

Workers' struggles - productive reconvertion - food industry - social and political radicalization Gran Rosario 


\section{BATALLAS OBRERAS EN CONTEXTOS DE RADICALIZACIÓN SOCIAL Y POLÍTICA EN LA AGROINDUSTRIA (GRAN ROSARIO, 1969- 1972)}

SILVIA SIMONASSI (ISHIR / UNR)

silviasimonassi@yahoo.com.ar

\section{VERÓNICA VOGELMANN (ISHIR-CONICET / UNR)}

veronicavogelmann@gmail.com

Existe cierto consenso en la historiografía que ubica al año 1969 -en especial con el estallido del "Cordobazo"- como el punto de inicio de una importante ola de conflictividad y radicalización obrera. Se ha enfatizado la centralidad de los trabajadores mejor pagos y calificados de las industrias dinámicas y se ha tendido a profundizar el análisis en el proceso de luchas y organización de los y las trabajadoras durante la primera mitad de la década del setenta. Sin embargo, ha sido preciso inscribir ese proceso, entendido como punto de inicio, en tradiciones y experiencias previas.

De modo que se ha tendido a revalorizar las luchas protagonizadas por diversos colectivos de trabajadores y trabajadoras a lo largo de la década. Así, se ha expuesto la importancia de la conflictividad acontecida a principios de los años sesenta y el método de ocupaciones fabriles que atravesó la industria del Gran Buenos Aires a principios de la década del sesenta, capitalizada durante el Plan de Lucha de la Confederación General del Trabajo -CGT- de 1964 en varias partes del país. ${ }^{1}$ Han sido estudiadas un conjunto de huelgas ubicadas al inicio del Onganiato, como la sostenida por trabajadores portuarios en diversos sitios del país en 1966 o ante el cierre de ingenios azucareros. ${ }^{2}$ Otras investigaciones han mostrado la importancia de luchas acontecidas durante 1968, como la de los trabajadores petroleros de Ensenada. ${ }^{3}$

\footnotetext{
${ }^{1}$ Schneider, Alejandro, Los compañeros. Trabajadores, izquierda y peronismo, 1955-1973, Buenos Aires, Imago Mundi, 2005 y "Algunas consideraciones sobre las ocupaciones fabriles en la década de 1960", en Trabajadores, Buenos Aires, Herramienta, 2009, pp. 911-127; Simonassi, Silvia y Vogelmann, Verónica, “Aliados incómodos. Tradiciones obreras y sindicales en Rosario a principios de los años sesenta”, Izquierdas, núm. 34, Santiago de Chile, julio, pp. 231-259 y "Pegar un chiflido y juntar gente. La conflictividad obrera en el Gran Rosario, 1955-1962", en Simonassi, Silvia y Dicósimo, Daniel (coords.), Trabajadores y sindicatos en Latinoamérica. Conceptos, problemas y escalas de análisis, Buenos Aires, Imago Mundi, 2018, pp. 151-171; Simonassi, Silvia, "El Plan de Lucha de la CGT argentina y las dinámicas regionales de la conflictividad en el Gran Rosario hacia mediados de la década de 1960", Revista Trabajo y Sociedad, núm. 33, Santiago del Estero, invierno 2019, pp. 391-411.

2 Snitcofsky, Valeria, "Villas de Buenos Aires y conflictos portuarios bajo el gobierno de Onganía", en Basualdo, Victoria (coord.) La clase trabajadora argentina en el siglo XX: experiencias de lucha y organización, Buenos Aires, Cara o Ceca, 2011, pp. 51-80; Nieto, Agustín, “Activación obrera y democracia. Experiencias micropolíticas de un grupo subalterno: Las obreras/os del pescado, Mar del Plata (1942-1966)", A Contracorriente, 9(1), 2011, pp. 175-202; Zapata, Ana Belén, "Portuarios en lucha: de la huelga, a la demanda por un "Puerto- Fábrica" Bahía Blanca-Ingeniero White (1966-1971)", Archivos de Historia del Movimiento Obrero y la Izquierda, núm. 11, 2017, pp.163-182; Mangiantini, Martín, "La huelga de 1966 en el Puerto de Buenos Aires ¿caso excepcional de resistencia o preludio de la radicalización?”, Avances del Cesor, núm. 20, junio 2019, pp.53-76; Nassif, Silvia, Tucumán en llamas. El cierre de ingenios y la lucha obrera contra la dictadura (19661973). Tucumán, UNT, 2016.

${ }^{3}$ Raimundo, Marcelo, "Grandes huelgas platenses durante la Revolución Argentina en perspectiva comparada", en Castillo, Cristian y Raimundo, Marcelo, El 69 platense, La Plata, Estudios Sociológicos Editora, 2012, pp.235-267;
} 
Desde diferentes ángulos de análisis, estos y otros trabajos han profundizado en conflictos que antecedieron a la etapa de ascenso de las luchas que se produjo tras el "Cordobazo" y que revelan la resistencia a las políticas de racionalización tanto implementada por los empresarios, como encarada a través de los planes económicos adoptados durante el período y que representaron experiencias que pudieron ser capitalizadas a fines de la década del sesenta. ${ }^{4}$

Quienes han investigado los procesos de lucha y organización producidos a partir del 69, por su parte, han enfatizado el papel de los trabajadores automotrices de Córdoba y los denominados sindicatos líderes ${ }^{5}$, tras lo cual, en otras áreas regionales, como el sur de Santa Fe, se tendió a ubicar en el centro del análisis a trabajadores de las industrias dinámicas, en particular en la zona norte del Gran Rosario y en Villa Constitución. En la primera de estas áreas, la reconstrucción del proceso de lucha y organización obrera se ha enfocado en la experiencia de los petroquímicos y en las expresiones de los trabajadores del cordón industrial al norte de la ciudad, donde se ubicaron las industrias dinámicas de capital extranjero a lo largo de la década, mientras en el segundo caso fueron los obreros siderúrgicos quienes estuvieron en el foco de las pesquisas. ${ }^{6}$ Recientes investigaciones han abordado la conflictividad en la industria alimenticia frigorífica, aceitera y molinera o en fábricas metalúrgicas de capitales nacionales. ${ }^{7}$

Sin embargo, desde la perspectiva de la historia social regional de los trabajadores, es una tarea pendiente profundizar el análisis en empresas y ramas específicas de la industria, para dar cuenta de las motivaciones, los rasgos y los resultados de las luchas emprendidas, los procesos de organización y las respuestas estatales y empresariales.

Este artículo forma parte de una investigación más amplia, orientada a repensar la conflictividad entre los y las trabajadoras de diversas ramas de la industria y del sector estatal en la larga década

Dawyd, Darío, “La 'huelga santa' de los petroleros de Ensenada. Petróleo, peronismo y política en el 68 argentino”, en Basualdo, Victoria (coord.) La clase trabajadora argentina en el siglo XX, op.cit, pp.81-114; Payo Esper, Mariel, "Una huelga para defender a la patria'. Reflexiones en torno a los trabajadores petroleros y la huelga del SUPE Ensenada de 1968", en Schneider, Alejandro y Ghigliani, Pablo (comps.) Clase obrera, sindicatos y Estado. Argentina (1955-2010), Buenos Aires, Imago Mundi, 2015, pp.23-42.

${ }^{4}$ Para un análisis más exhaustivo de las últimas investigaciones, consultar: Simonassi, Silvia y Schneider, Alejandro, "Debates y perspectivas en torno a la historia reciente de los trabajadores en Argentina", en Águila, Gabriela; Luciani, Laura; Seminara, Luciana y Viano, Cristina (coords.) La Historia Reciente en Argentina. Balances de una historiografía pionera en América Latina, Buenos Aires, Imago Mundi, 2018, pp.39-54.

5 Brennan, James, "El clasismo y los obreros. El contexto fabril del «sindicalismo de liberación» en la industria automotriz cordobesa 1970-75", en Desarrollo económico, núm. 125, abril junio 1992, pp.3-22; El cordobaz̧. Las guerras obreras en Córdoba, 1955-1976, Buenos Aires, Sudamericana, 1996 y Gordillo, Mónica, Córdoba en los '60. La experiencia del sindicalismo combativo, Córdoba, Universidad Nacional de Córdoba, 1999; Mignon, Carlos "Insubordinación obrera en Córdoba. Las "huelgas salvajes" de 1970-1971 en la industria metalmecánica y la experiencia del Sitrac clasista", en Archivos de bistoria del movimiento obrero y la izquierda, núm 4, 2014, pp. 77-98; Laufer, Rodolfo, "El clasismo en el SMATA Córdoba, 1966-1972" en Rupar, Brenda; Costilla, Ana y Galafassi, Guido (eds.), Dirán bubo gigantes aquí: iqquierda, peronismo y clase obrero en los '60 y '70, Buenos Aires, Theomai, GEACH, Extramuros ediciones, 2018, pp.115-137.

${ }^{6}$ Aguila, Gabriela y Viano, María Cristina, “Trabajador@s y militantes. Algunas vertientes de la izquierda peronista del norte al sur del cordón industrial del Gran Rosario entre 1969 y 1976. Una aproximación desde la historia oral”, en Anuario N¹9, Rosario, 2002, pp.179-198; Cerio, Débora, "Revisando los relatos sobre una experiencia de organización obrera: el Sindicato de Obreros y Empleados Petroquímicos Unidos en los años '70", en Taller. Revista de Sociedad, Cultura y Política, núm 24, 2007. Para Villa Constitución: Santella, Agustín y Andújar, Andrea, "El Perón de la fábrica éramos nosotros". Las luchas metalúrgicas de Villa Constitución 1970/1976, Buenos Aires, Desde el Subte, 2007; Basualdo, Victoria, "La organización sindical de base en Acindar Villa Constitución en la segunda ISI: aportes para la comprensión de sus particularidades y su significación histórica”, en Basualdo, Victoria (coord.) La clase trabajadora argentina.... op.cit., pp. 235-278; Rodríguez, Ernesto y Videla, Oscar (comps.), El villazo. La experiencia de una ciudady su movimiento obrero, Santa Fe, Ministerio de Derechos Humanos, 2013.

${ }^{7}$ Vogelmann, Verónica, "Los trabajadores de la carne en el Gran Rosario. Organización gremial y conflictividad laboral (1969-1976)", Historia Regional núm. 31, Villa Constitución, 2013, pp.115-138; Simonassi, Silvia, "Procesos estructurales y conflictividad laboral durante los años sesenta en el Gran Rosario, Argentina", LASA Barcelona, España, ponencia, 2018; Carminati, Andrés, "Elementos extraños con brazaletes rojos. Radicalización obrera y lucha armada en una metalúrgica mediana de la ciudad de Rosario (1973-1976), en Ciriza, Alejandra; Graselli, Fabiana y Rodríguez Agüero, Laura (orgs.), Tiempos disruptivos. Lecturas sobre la centralidad de la politica en los 70, Ediunc, Mendoza, 2018. 
del sesenta en la región. Se propone revisar las batallas obreras acontecidas en el Gran Rosario luego del "Cordobazo" (mayo de 1969) y de los "Rosariazos" (mayo y setiembre de 1969), prestando atención a ramas escasamente exploradas, desde una perspectiva que articule transformaciones estructurales, lucha y organización: la frigorífica y la aceitera. Se propone inscribir este proceso en otro más general, regional y nacional, sin perder de vista el objetivo central, cual es revisar los conflictos acaecidos en ramas más tradicionales de la industria, en crisis o reconversión, azotadas por cesantías y despidos, donde también se concentró el activismo más radicalizado y que despertó preocupación en los servicios de inteligencia y los sectores empresarios. Develamos así las contradicciones del proceso de radicalización en el marco de luchas defensivas, por la conservación de fuentes de trabajo frente a suspensiones, cesantías y cierres.

En una primera parte sintetizamos la situación que atravesaban las ramas analizadas, como factor explicativo del estallido y el devenir del proceso de luchas, al tiempo que presentamos un breve panorama de la situación sindical como marco para comprender las disputas intra e intergremiales. En el segundo y tercer apartado, articulamos estas dimensiones en el análisis de los conflictos desarrollados en dos zonas del Gran Rosario: la zona sur (Villa Gobernador Gálvez) y norte (desde Granadero Baigorria hasta Puerto General San Martín), donde se desarrollaron conflictos en el frigorífico Swift y en Molinos Río de la Plata, respectivamente. Finalmente, presentamos un conjunto de conclusiones.

\section{La industria agroalimentaria, crisis y reconversión}

En 1966 las Fuerzas Armadas dieron un golpe encabezado por el Gral. Onganía. La política económica del nuevo gobierno consistió en la devaluación del peso en un 40\%, y la liberación del mercado cambiario. El impulso al desarrollo industrial iniciado por el desarrollismo frondicista se acopló a una política de retenciones a las exportaciones tradicionales. Paralelamente, encararon una fuerte ofensiva contra los sectores industriales "ineficientes" como los ingenios azucareros, lo cual convirtió a la provincia de Tucumán en uno de los epicentros de la conflictividad. Junto a los efectos del ajuste en el ámbito del Estado, la crisis de las ramas tradicionales de la industria empujó a la lucha a los trabajadores de esos sectores. La dictadura estableció el arbitraje obligatorio entre obreros y patrones, lo cual en los hechos limitaba el derecho a huelga, se suspendieron las Comisiones Paritarias, se estableció un estricto control sobre las organizaciones sindicales, se efectuó un incremento salarial por decreto y su posterior congelamiento. El gobierno intervino además los gremios más castigados por las políticas de racionalización, como la Federación Obrera Tucumana de la Industria del Azúcar (FOTIA) y la Unión Ferroviaria (UF), entre otras medidas adversas orientadas a los sectores trabajadores. ${ }^{8}$

Las políticas económicas del Onganiato representaron una profundización de la tendencia iniciada durante el frondicismo, a la instalación de capitales extranjeros en la zona norte del cordón industrial del Gran Rosario. Según la Encuesta Industrial de 1969, que relevó información de 88 empresas de la región, en la zona norte predominaban las empresas correspondientes a las ramas química, petroquímica y papel y maquinarias y equipos industriales, que acaparaban el $90 \%$ de las ventas totales. Hegemonizaba el gran capital extranjero. En la zona del cordón industrial al sur de Rosario, predominaba la rama de alimentos y bebidas, que concentraba más del $90 \%$ de las ventas zonales. En la citada muestra se incluyeron las más grandes empresas de cada rama, por ejemplo Swift, Estexa, John Deere y Celulosa.?

\footnotetext{
${ }^{8}$ Gordillo, Mónica, Córdoba en los sesenta, op.cit; Viano, Cristina: "Una ciudad movilizada, 1966-1976", en Pla, Alberto (coord.): Rosario en la historia (de 1930 a nuestros días), UNR Editora, 2000; tomo II, Rosario, pp. 23-119.

${ }^{9}$ La Encuesta fue trabajada exhaustivamente por Jorge Sgrazzutti: "Industria y desarrollo. El caso del Área Metropolitana del Gran Rosario (1958-1974)", Rosario, mimeo, 1991 y contrastada con Censos Provinciales y Nacionales del período.
} 
En efecto, durante estos años se va consolidando el perfil industrial del cordón industrial del Gran Rosario. El norte -que incluye a las localidades de San Lorenzo, Puerto San Martín, Fray Luis Beltrán, Capitán Bermúdez y Granadero Baigorria-, va cobrando un perfil dinámico, ligado a industrias de punta. En el cordón sur, principalmente en Villa Gobernador Gálvez, el perfil industrial era heterogéneo dada la expansión de una industria metalúrgica de peso significativo, sin embargo, la rama de la alimentación y principalmente la industria frigorífica, ha sido históricamente significativa en términos socio-económicos.

En la ciudad de Rosario el 85\% de las ventas provenían de una combinación de estructuras viejas y nuevas, o de industrias vegetativas y dinámicas, con predominio de las primeras. En el caso del "perfil metalmecánico" que ostentaba la ciudad desde hacía años, se materializaba en la proliferación de empresas de la rama de diferente tamaño, diseminadas en distintas barriadas de la ciudad. ${ }^{10}$ En definitiva, y en términos generales la región acompañó la expansión industrial que se verificaba en las principales regiones del país.

Sin embargo, estas tendencias estuvieron acompañadas de procesos de reconversión industrial que implicaron cierres temporarios o definitivos de plantas y conmovieron el panorama social de la década. En ese escenario, los sectores agroindustriales frigoríficos y aceiteros con presencia en la región norte y sur de Rosario estuvieron sujetos a profundas transformaciones que impactaron fuertemente en los colectivos obreros a través de suspensiones, despidos y cierres de plantas. Durante estos años ambas industrias atravesaron procesos de reconversión que implicaron una significativa reducción de puestos de trabajo.

La industria frigorífica, desde la década del cincuenta, ingresó en un proceso de estancamiento productivo como consecuencia del descenso paulatino en su performance exportadora. Paralelamente, se fue desplegando un proceso de descentralización del sector, aumentando significativamente las unidades productivas, a partir de la expansión de un nuevo tipo de establecimiento de capitales nacionales y con estructuras de dimensiones menores. ${ }^{11}$ Por su parte, los grandes frigoríficos de capitales extranjeros que habían oligopolizado la producción durante el período anterior, ingresaron en un proceso de crisis que culminó con el cierre de la mayoría de ellos. El único frigorífico de la industria grande que sobrevivió en Argentina fue el Swift de Villa Gobernador Gálvez, sin embargo, esto no impidió que el proceso de reconversión de la rama impactara fuertemente en su colectivo obrero en términos de suspensiones y despidos sistemáticos.

Por su parte, la industria aceitera también se verá atravesada por transformaciones sustanciales que se desarrollaron durante la década del setenta y dieron como resultado un paulatino proceso de consolidación del complejo industrial en la economía del país. ${ }^{12}$ Las tendencias generales que se fueron perfilando por esos años apuntalaron un proceso de concentración y centralización de capital (las empresas que operaban en la actividad se redujeron de 46 en 1973 a 36 en 1984), y

\footnotetext{
${ }^{10}$ Predominaban las pequeñas, en un porcentaje del $72 \%$ del total, las medianas representaban el 17\% y las de tamaño intermedio y grande registraban el 7,5\% y el 3,5\%, respectivamente. Ideario Metalúrgico, núm. 9, julio-agosto de 1970 (Archivo Asociación de Industriales Metalúrgicos de Rosario). La muestra involucró 613 empresas: 442 a Rosario, 124 a otras ciudades de la provincia, 34 de la provincia de Córdoba, 5 de la provincia de Buenos Aires, 8 a otras.

${ }^{11}$ En Villa Gobernador Gálvez se inauguró en 1956 el frigorífico Subproductos Ganaderos Rosario S.A. (Sugarosa) y a principios de la década del '60, las plantas de las empresas Paladini, Villa Diego, Litoral Argentino S.A. y Lequio. En la zona sur de Rosario se estableció el frigorífico La Tropa y se industrializó la empresa familiar La Jamonera. En el año 1962 se instaló la Corporación Argentina de Productores de Carne (CAP).

12 Pérez Barreda, Natalia; Kofman, Marco y Abraham, Lavih "El capital extranjero en la transformación de la industria aceitera argentina en las últimas décadas (1970-2010)", Trabajo elaborado en el marco de los proyectos La industria aceitera en la provincia de Santa Fe en el largo plazo (1880-1990) (1ECO132-UNR), Frid, Carina (dir.) y Empresas e inversiones extranjeras en la economía argentina. Un análisis histórico de largo plazo 1870-2001 (PICT-UNR), Lanciotti, Norma (dir.), Facultad de Ciencias Económicas, UNR. 2013, inédito.
} 
especialización productiva, donde adquiere relieve el procesamiento de soja y girasol en detrimento de otros cultivos como lino y maní. ${ }^{13}$

Inscriptas en esta dinámica general, las empresas aceiteras ubicadas en la provincia de Santa Fe y en el cordón norte de Rosario realizaron despidos y suspensiones masivas, al tiempo que se produjeron cierres de plantas, el más significativo de los cuales fue el de la planta Molinos Río de La Plata de San Lorenzo, perteneciente al grupo Bunge y Born.

A fines de los sesenta y como resultado de la escasa respuesta de las direcciones tradicionales del movimiento obrero a las crecientes demandas, surgieron y se consolidaron nuevos liderazgos obreros y sindicales y en la cúpula, el predominio de la CGT fue respondido con la creación de la CGT de los Argentinos (CGTA) en 1968, que se consolidó en el interior del país, promoviendo prácticas sindicales democráticas y combativas y la unidad obrero-estudiantil.

En Rosario la CGTA reunió diversos gremios, en particular estatales, como la Asociación de Trabajadores del Estado (ATE), la Unión del Personal Civil de la Nación (UPCN), los telefónicos, los navales, la UF, la Fraternidad (LF), Gas del Estado y también gráficos, calzado, ceramistas, seguro, locutores, operadores cinematográficos y publicidad. Mientras tanto, los "poderosos sindicatos industriales permanecieron al margen de esta experiencia, la mayoría de ellos férreamente controlados por los sectores burocráticos". ${ }^{14}$

En 1969 se produjeron los dos "Rosariazos" y entre ambos momentos, el "Cordobazo" -sin duda la mayor insurrección urbana, combinada con protesta obrera y rebelión popular- y como consecuencia del mismo, los desplazamientos de los Ministros de Economía y del Interior. En la ciudad, en setiembre de 1969 los protagonistas fundamentales fueron los trabajadores, pues los acontecimientos conocidos como el segundo Rosariazo se iniciaron con un paro por tiempo indeterminado declarado por los ferroviarios del Mitre, como culminación de un malestar provocado por una arremetida más general hacia los trabajadores del sector iniciada tiempo antes, medida de lucha que se extendió a todo el país. ${ }^{15}$

Tras estos estallidos, se abrió el citado proceso de radicalización social y política que devino en el inicio de las acciones de las organizaciones político militares y en la actuación de corrientes clasistas y combativas vinculadas con distintas vertientes de izquierda. En Rosario, tras el primer Rosariazo, se unificó la CGT, conteniendo a la mayoría de los sindicatos de la región y albergando a las más heterogéneas expresiones político-gremiales. En respuesta a esta unificación, se creó la Intersindical de Gremios de San Lorenzo (1969-1973), inicialmente surgida como "alianza sindical defensiva" para tornarse posteriormente una organización democrática, clasista y combativa, antecesora de la Coordinadora de Gremios Combativos (1975-1976). ${ }^{16}$

\section{"Trabajo inhumano", inestabilidad y superexplotación: el Swift y la militancia política y sindical}

Como hicimos referencia, entre los años 1955 y 1974 decayó la performance argentina en materia de exportación de carnes, en buena medida como producto de transformaciones en el mercado mundial. Sin embargo, en el sur del Gran Rosario a principios de la década del setenta se designaba

\footnotetext{
${ }^{13}$ Gutman, Graciela y Feldman, Silvio, La industria aceitera en Argentina. Un caso de expansión productiva orientada al mercado mundial, Documento de trabajo N³2, Buenos Aires, CEPAL, 1989.

${ }^{14}$ Viano, Cristina, "Una ciudad movilizada...", op.cit., p.41.

${ }^{15}$ Hasta el momento, el trabajo más sistemático sobre el tema es: Pérez, José y Viano, María Cristina, "El 69: del mayo rosarino al Rosariazo", en Berrotarán, Patricia y Pozzi, Pablo (comps.), Estudios inconformistas sobre la clase obrera argentina, 1955-1989, Buenos Aires, Ediciones Letra Buena, 1994, pp. 89-114.

${ }^{16}$ Ceruti, Leónidas y Resels, Mariano, Democracia Directa y gestión obrera. El SOEPU, la Intersindical de San Lorenzo y la Coordinadora de Gremios (1962-1976), Rosario, Ediciones del Castillo, 2006.
} 
a la ciudad de Villa Gobernador Gálvez con el título de "Capital Provincial de la Industria de la Carne" por la elevada concentración de establecimientos frigoríficos.

Además de la ya señalada conflictividad producida en la zona norte del cordón industrial del Gran Rosario, hubieron industrias en crisis y reconversión, de antigua instalación, que fueron epicentro de importantes procesos. Tal fue el caso del frigorífico Swift, cuyos trabajadores protagonizaron la "Lucha del Frío" que se desarrolló en el mes de agosto de 1969, entre el primer y el segundo Rosariazo. El conflicto comenzó en la sección Picada, por problemas derivados de las bajas temperaturas registradas en la sección y la falta de elementos de trabajo e indumentaria especial. En los días sucesivos, la contienda se extendió a todo el frigorífico y desembocó en la renuncia del Secretario General del Sindicato.

Este proceso fue protagonizado por la agrupación La Chaira, cuyo epicentro de actuación era el frigorífico Swift y contenía en su interior a activistas pertenecientes a diversas corrientes y partidos (Partido Comunista -PC- y, luego de la ruptura de esa organización en 1968, el Partido Comunista Revolucionario -PCR-, Socialismo Revolucionario -SR; Partido Revolucionario de los Trabajadores -PRT-, Vanguardia Comunista -VC-, Partido Socialista de los Trabajadores -PST-, entre otras). La Chaira se estructuró identificando problemáticas cotidianas que se repetían en las distintas secciones del frigorífico, dándoles difusión y organizando las denuncias. Desde sus orígenes postulaba su accionar en torno a la "lucha sindical clasista" e independiente. ${ }^{17}$

En el proceso de la lucha del frío la organización gremial lista Blanca y Negra se posicionó en el Sindicato Industria de la Carne de Rosario. Estaba liderada por dirigentes peronistas, quienes a través de la intervención llevada adelante por la Federación Nacional asumieron la conducción. A lo largo del conflicto, la Federación y la intervención del Sindicato minimizaron la magnitud y el acatamiento a los paros y repudiaron la actitud de grupos extremistas "ajenos al gremio", proclamando la "vía orgánica" como única alternativa para la solución de los problemas laborales. ${ }^{18}$

Swift suspendió aproximadamente dos mil trabajadores, despidió y avaló detenciones de activistas y dirigentes de la agrupación La Chaira, no obstante lo cual su presencia en el espacio laboral se mantuvo como un polo de atracción de militantes y agrupaciones de izquierda. Mientras que la lista Blanca y Negra se consolidó al frente del Sindicato local, haciendo eje centralmente en su función mutualista. ${ }^{19}$

El frigorífico Swift como epicentro del dinamismo económico del sur del Gran Rosario comenzó a resquebrajarse hacia 1969, momento en que fue adquirido por el grupo económico Deltec. El renombrado "Caso Deltec" 20 refiere a las maniobras financieras de carácter fraudulento desarrolladas por el grupo en detrimento de la rentabilidad de la compañía, como por ejemplo la adquisición por parte de la casa matriz de la producción del frigorífico a un precio muy inferior a los dictados por el mercado y el cobro anticipado de créditos de capital. Esas maniobras, fueron denunciadas por el activismo de izquierda. ${ }^{21}$ En ese marco, a principios de la década de setenta fue declarada la quiebra de todos los activos de Swift. ${ }^{22}$

Hacia octubre de 1970 se produjo la paralización de las plantas que Swift tenía en las localidades de Berisso, Ensenada y Villa Gobernador Gálvez, al tiempo que se multiplicaban los despidos y

\footnotetext{
${ }^{17}$ Entrevista a trabajador de Swift-Rosario entre 1971 y 1973, sección picada. Militante agrupación la Chaira, dirigente PST. Rosario, octubre 2007.

${ }^{18}$ La Tribuna, Rosario, 6 de agosto de 1969. (Archivo Hemeroteca de la Biblioteca Argentina -AHBA-)

${ }^{19}$ Entrevista, op. cit.

20 Treviño, Pepe, La Carne Podrida. Crónica en torno a la quiebra Swift-Deltec. Buenos Aires, Del Salto, 1972. Para más detalles sobre el proceso de quiebra del grupo Deltec ver Realidad Económica núm. 7 y 8, 1972; y núm. 12, 1973.

21 "La agrupación "El Activista de la Carne" (lista gris) ante la quiebra del Swift", Berisso, 16 de noviembre de 1971. (Archivo Digital Fundación Pluma -ADFP-), disponible en: http:// fundacionpluma.info:8080/xmlui/

${ }^{22}$ Las plantas de Berisso y Villa Gobernador Gálvez, doce sucursales que componían la red de comercio interior, y las cremerías ubicadas en las provincias de Buenos Aires y Santa Fe.
} 
suspensiones. En Rosario, la dirección sindical comenzó a exigir la implementación de una política de carnes coherente y seria, tendiente a que créditos, tributos y renovación tecnológica se pusieran al servicio del progreso y de los intereses nacionales y populares. ${ }^{23}$ Asimismo, realizaron paros parciales y movilizaciones en defensa de las fuentes de trabajo y, principalmente, por el pago de la garantía horaria.

La situación de los trabajadores del frigorífico Swift ocupaba especialmente a los Servicios de Inteligencia y la Policía Provincial, quienes en sus informes diarios seguían la marcha de los acontecimientos. Así, el 21 de octubre informaban que las suspensiones habían ascendido a 1.018 y que el gremio sesionaba de manera permanente e impulsaba paros de media hora. Al día siguiente, daban cuenta de la detención de activistas ligados al Comité Zona Industrial "Juan Ingalinella", Zona Sur del Partido Comunista, Federación Juvenil, quienes arrojaron volantes aludiendo a la situación en la industria frigorífica en general y al Swift en particular. Ese mismo día ya informaban que a las suspensiones se les sumaban otras tres mil. Las descripciones esbozadas en los documentos de inteligencia indican que los movimientos de protesta no alcanzaban el nivel de radicalidad esperado por las fuerzas represivas:

“... teniendo en cuenta la especial situación por la que atraviesa la ciudad de Rosario, con cuatro mil obreros suspendidos en el Swift, los actos turbatorios (sic) no tuvieron la envergadura que era de esperarse, llamando poderosamente la atención la escasa cantidad de atentados cometidos en la noche anterior al paro" ${ }^{24}$

dispuesto por la CGT, que contó en la ciudad con una adhesión total. La prensa también siguió con detenimiento la situación, informando que entre octubre de 1970 y febrero de 1971 las suspensiones pasaron de 500 a 6.400 operarios. $^{25}$

En diciembre de 1970 Swift solicitó la convocatoria de acreedores. Ante la perspectiva de un conflicto de difícil solución, la dirigencia sindical concentró el reclamo en la exigencia de reapertura de las plantas de Swift. Por su parte, La Chaira desarrolló distintas actividades solidarias con el fin de profundizar prácticas de militancia en el espacio barrial, aunque vio menguar significativamente su fuerza gremial. Asimismo, los trabajadores contaron con la solidaridad activa de los comerciantes del barrio, quienes se organizaron alrededor de la Comisión de Comerciantes e Industriales Pro Recuperación del Frigorífico Swift. ${ }^{26}$

Es posible afirmar que aquel momento se caracterizó por la participación en el espacio local, tanto laboral como barrial, de agrupaciones político-gremiales de muy diverso espectro que, diferenciándose de la cúpula sindical, promovían instancias de movilización y organización autónomas. Algunas, como La Chaira, tenían una existencia previa, mientras que otras habían emergido en el contexto de quiebra, entre estas destacamos a la Celeste y Blanca, agrupación gremial de extracción peronista que mantendrá una presencia prolongada al interior del gremio de Rosario.

Un elemento importante a considerar es que el conflicto por el cierre en Rosario terminó siendo de corta duración si lo comparamos con los producidos en otras localidades del país en donde la empresa poseía plantas. ${ }^{27}$ En la región, Swift mantuvo la operatividad a través del alquiler de la

${ }^{23}$ La Capital, "Solicitada", Rosario, 5 de octubre de 1970. (AHBA), Rosario.

24 Policía de la Provincia de Santa Fe, Servicio de Inteligencia y Comunicaciones, "Memorandum", Santa Fe, núm. 1412, 21 octubre de 1970; núm. 1413, 22 de octubre de 1970 y 1414, 23 octubre de 1970. (Archivo Provincial de la Memoria de Santa Fe -APMSF-).

${ }^{25}$ Swift suspendió a 500 operarios, los cuales pasaron a ser 4.200 en pocos días 4.200 , hasta ascender finalmente a 6.400. La Tribuna, Rosario, 20 de octubre de 1970 y 9 de febrero de 1971; La Capital, Rosario, 22 de octubre y 24 de noviembre de 1970. (AHBA), Rosario.

${ }^{26}$ La comisión nucleaba a unos 250 pequeños y medianos comerciantes de la zona sur de Rosario. Ante el peligro de desaparición de un importante mercado de consumo realizaban cierres de protesta reclamando la conservación de la fuente de trabajo para sus clientes. La Capital, Rosario, 11 de enero de 1971. (AHBA), Rosario.

${ }^{27}$ Vogelmann, Verónica, "Los trabajadores de la carne...", op. cit. 
planta a la empresa de alimentos estadounidense Campbell Soup. ${ }^{28}$ El temprano interés que Campbell Soup demuestra sobre Swift Rosario se vincula con que era la planta más nueva de la empresa y estaba en proceso de reconfiguración productiva a favor de la elaboración de productos para el mercado externo como conservas y carnes cocidas. ${ }^{29}$ De manera que, a partir de marzo de 1971 en Rosario comenzaron a realizarse reincorporaciones de personal que llegaron hasta tres mil operarios, menos de la mitad de los trabajadores con los que contaba la empresa antes del cierre. Así, en el ámbito local, arribaron a una solución parcial de los despidos ${ }^{30}$ y fue precisamente, en el marco de este proceso, donde muchos activistas y militantes vinculados a La Chaira no volvieron a ingresar al frigorífico. ${ }^{31}$

Paralelamente, durante este período sobresalieron las acciones llevadas adelante por organizaciones político militares, especialmente por el Ejército Revolucionario del Pueblo -ERP- que efectuó numerosas expropiaciones de mercadería y repartos de víveres en zonas carenciadas del Gran Rosario, la mayoría en los barrios circundantes al frigorífico. ${ }^{32}$

En mayo de 1971 realizaron en el Gran Rosario la primera acción de gran envergadura, al secuestrar a Stanley Sylvester, gerente de la planta local de Swift y cónsul honorario de Inglaterra. El ERP sometió a Sylvester a "juicio revolucionario". En su figura quedaban sintetizados los "enemigos del pueblo argentino: el imperialismo británico y el poderoso monopolio yanqui DELTEC Internacional". La organización denunciaba al Ministro de Economía, Krieger Vasena, como "personero de DELTEC o de otros monopolios" y al propio General Lanusse "cuya familia, además de otros negociados, es una de las principales propietarias de hacienda y proveedoras de ganado del frigorífico como ya lo ha declarado el señor Sylvester en el curso de los interrogatorios". 33

Sin embargo, el eje fundamental de la intervención consistió en la denuncia de las condiciones de vida y trabajo de los obreros de la carne "los peor pagos de la industria, sujetos a despidos y suspensiones arbitrarias". Siempre según el ERP, la carne se había convertido en un "artículo de lujo para el pueblo", permanecían obreros suspendidos y salarios sin pagar. Existía además un "régimen de trabajo inhumano, los topes de producción son inalcanzables... se ven a diario compañeros con heridas en las manos, enfermos, que son enviados de vuelta al trabajo bajo amenaza de suspensiones y despidos". Por su parte, resaltaban que la dirigencia sindical no convocaba a acciones de lucha. ${ }^{34}$

Denunciaron además el importante despliegue represivo que desbordó el barrio para extenderse a la región: "Tropas especialmente entrenadas contra la guerrilla urbana ocuparon prácticamente la ciudad, atronándola con sirenas con la vana intención de meter miedo. Se sucedieron los allanamientos, las detenciones. Muchas casas fueron verdaderamente saqueadas por la Policía Federal, sobre todo las más humildes; muchas personas inocentes fueron apaleadas y torturadas bajo el pretexto de la búsqueda del Señor Sylvester". ${ }^{35}$

\footnotetext{
${ }^{28}$ Campbell Soup Company nació en 1869 en Estados Unidos. Sobresale internacionalmente por la producción de sopas condensadas, uno de los primeros alimentos "prácticos" del mundo. Durante el siglo XX, además de diversificar su producción, adquiere industrias alimenticias en distintos lugares del mundo.

${ }^{29}$ Gresores Graciela, “Apuntes para la historia del frigorífico Swift en Argentina (1957-1980)”, en Azcuy Ameghino, Eduardo; Bordas, Marcelo; Gresores, Gabriela y Martínez Dougnac, Gabriela, El Complejo agroindustrial de la carne vacuna argentina, 1960-1996, Cuadernos de PIEA, Buenos Aires, 1998, pp. 103-125; Treviño, Pepe, La Carne Podrida ..., op. cit. 30 A nivel nacional el Estado intervino la firma y tomó su administración hacia finales del año 1971.

31 Vogelmann, Verónica, "Los trabajadores de la carne...", op. cit.

${ }^{32}$ La Tribuna, Rosario, 21 de enero, 12 y 27 de febrero, 1 y 26 de marzo y 2 abril de 1971. (AHBA) Rosario.

${ }^{33}$ El Combatiente, "El secuestro del cónsul", núm. 56, 31 de mayo de 1971. (Archivo digital El Topo Blindado -ADTB-

), disponible en: http://eltopoblindado.com

${ }^{34}$ El Combatiente, "El secuestro del cónsul”, núm. 56, 31 de mayo de 1971. (ADTB)

${ }^{35}$ Estrella Roja, "El gerente y la justicia del pueblo", núm. 3, junio de 1971. (Archivo Ruinas Digitales -ARD-), disponible en: http://ruinasdigitales.com
} 
La organización exigió a la empresa la reincorporación y el pago de lo adeudado a los trabajadores suspendidos; el cese del trato policial por parte de los jefes; la disminución del frío en las secciones que afectaban la salud de los trabajadores e impedía que mujeres embarazadas pudieran trabajar; y la indemnización de 25 millones de pesos en alimentos. Además, reclamaron repartos de frazadas, carne y útiles escolares. Luego de obtener algunas de las demandas solicitadas, como la reincorporación de personal suspendido, el cónsul fue liberado tras siete días de secuestro. ${ }^{36}$

Como se relata, tras esta acción, se advierte la profusión de mecanismos represivos, con intervención de la policía y el ejército en los barrios cercanos a Swift. Se registraron detenciones de vecinos acusados por "delitos de complicidad" al aceptar mercadería distribuidas por el ERP en el marco de las expropiaciones y repartos de alimentos. ${ }^{37}$ Sin embargo, la presencia de las organizaciones armadas en el Swift se mantuvo, mediante su participación en la Lista Rosada y aunque disminuyeron los repartos de víveres, continuaron los secuestros a directivos, como el acontecido hacia principios de 1974, sobre el gerente de relaciones industriales Vallocchia. ${ }^{38}$

Desde mediados de la década del sesenta los esfuerzos de diversas agrupaciones de izquierda se enfocaron en el Swift. Espacio caracterizado por una gran concentración de trabajadores que, en su mayoría, realizaban tareas que requerían escasas calificaciones y cobraban bajos salarios y donde, además, tras la pérdida por parte del PC del sindicato en 1962, se consolidó una corriente peronista tradicional. $^{39}$ De manera que, las acciones de organizaciones armadas como el PRT-ERP en el frigorífico a principios de la década siguiente no se asentaba "en un vacío, sino que se recuesta sobre una presencia previa que se remonta a la segunda mitad de la década del '60 y que en los últimos tiempos se había visto acrecentada por un esfuerzo político más sostenido por organizar, no sólo a los trabajadores, sino también a los residentes de la zona". "Para otras vertientes, como el Peronismo de Base (PB) -de fuerte presencia en la zona norte-, militar en el Swift era como "gastar pólvora en chimango", dada la caracterización que hacían de la mano de obra como tradicional, "inestable y superexplotada", en otras palabras, " "una clase obrera estanca”." ${ }^{41}$ Cabe señalar que estas lecturas no eran exclusivas del PB; por el contrario, un militante del PRT al ser indagado sobre la presencia del partido en el frigorífico Swift comentaba:

\begin{abstract}
"Nosotros teníamos una mala caracterización del movimiento obrero [...] a nosotros nos impresionaba la concentración y no teníamos en cuenta la calidad sino la cantidad [...]. Nos parecía que era el frente principal y durante [un] tiempo estuvimos engañados, hasta que nos dimos cuenta; abriendo más hacia el cordón industrial del Paraná, San Lorenzo, donde ahí estaban las grandes fábricas realmente de la clase obrera más avanzada. Entonces, justamente, ahí nosotros después comenzamos a centrar en los obreros metalúrgicos." ${ }^{\text {"2 }}$
\end{abstract}

\title{
"No podemos dejar de estar orgullosos de la solidaridad brindada": El conflicto de Molinos Río de la Plata y la Intersindical de Gremios de San Lorenzo
}

\footnotetext{
36 La Tribuna, Rosario, 23, 24, 25, 26, 27, 28, 29, 30 y 31 de mayo; 1 y 2 de febrero de 1971, (AHBA), Rosario; Filme Swift, dirigido por Raymundo Gleyzer, Argentina, 1971.

37 La Tribuna, Rosario, 17 y 27 de julio de 1971, (AHBA), Rosario.

${ }^{38}$ La Tribuna, Rosario, 26 y 28 de febrero de 1974, (AHBA), Rosario.

39 Pasquali, Laura, "Éramos jóvenes, pero también obreros" Políticas y experiencias de inserción del PRT-ERP en el Gran Rosario", en Pasquali, Laura y Videla, Oscar, El contenido de los conflictos. Formas de la lucha sociopolítica en la historia argentina reciente. 1966-1996", Rosario, La quinta pata y Camino Ediciones- Historia Regional libros, 2010, pp. 25-42.

${ }^{40}$ Scoppetta, Laura y Torres, Pablo, "La apuesta armada. Notas sobre la política sindical del PRT-ERP, (1965-1976), inédito, p.137.

${ }^{41}$ Citado en Águila, Gabriela y Viano, Cristina, “Trabajador@s y militantes...”, op. cit. p. 189. Subrayado en el original. Para una caracterización del Peronismo de Base en Rosario, la delimitación con otras vertientes del peronismo sindical y el devenir posterior de parte de su militancia, consultar el citado artículo.

${ }^{42}$ Entrevista realizada por Verónica Vogelmann a militante de La Chaira y del PRT-ERP. Rosario, mayo de 2009.
} 
En un registro similar, el de las industrias en reconversión y crisis, donde la conflictividad se articuló con el proceso de radicalización política, se ubica el caso del cierre de la planta de aceite comestible que el grupo Bunge y Born tenía instalada en la ciudad de San Lorenzo, en el cordón norte.

Ejecutivos de la propia empresa informaron que en 1967 Molinos había decidido la renovación de la planta de Avellaneda, teniendo en cuenta la obsolescencia de sus equipos -algunos que databan de 1936- y la voluntad de incrementar la producción y la productividad, apuntando a triplicar los volúmenes procesados, abaratar costos y elevar los niveles competitivos hacia los países de mayor crecimiento industrial, con el fin de obtener saldos exportables. Sin embargo, esgrimían el escaso incremento de producción de oleaginosas como causante de la imposibilidad de cumplir las metas. Según la misma fuente, la producción total de aceites comestibles entre 1967 y 1970 había crecido solo de 471.000 toneladas a 486.000. Ante tal situación, la solución encontrada fue cerrar el establecimiento de "condiciones económicas menos idóneas". ${ }^{3}$

Según los dirigentes del Sindicato Obreros y Empleados Petroquímicos Unidos (SOEPU), en Avellaneda la empresa contaba con un mercado más extenso, ahorraban costos de flete, poseían puerto con salida al mar para la exportación, y se registraba "una impresionante desocupación que posibilita la elección de un personal dócil y porque (quien puede asegurar que no importa), no existe una Intersindical de Gremios más o menos combativa”. Sin negar la escasez de semillas de girasol, era la lógica capitalista de inversiones fáciles y rentables lo que explicaba la escasa cantidad de hectáreas cultivadas. También señalaban la descapitalización y la falta de modernización como factores a considerar. ${ }^{44}$ Según dirigentes del gremio aceitero, la planta de Avellaneda poseía la capacidad de trabajar 1200 toneladas diarias de semillas, frente a 500 de la planta de San Lorenzo, con "instalaciones mucho más modernas, la mano de obra tiene apenas una incidencia del 3 al 4\%". Y otro señalaba "la fábrica no da pérdida... en la caja de aceite de 12 botellas de 1 litro y medio en cada una ganan más del ciento por ciento y envasan de 40 a 50 mil cajas por día. Se vende el aceite al mayorista a $\$ 4.800$ y ellos gastan en la producción $\$ 2200$. Lo que realmente quiere la empresa con su planta de Avellaneda es ganar sumas fabulosas". ${ }^{45}$

En rigor, como adelantamos, comenzaba a visualizarse una tendencia a la concentración que la propia Federación Nacional de sindicatos aceiteros advertía: "No estamos en contra de ninguna empresa que sea chica o grande, entendemos que no pueden cerrar todas las fábricas de aceite, y quedar la industria aceitera monopolizada en cinco o seis fábricas nada más." Además de la falta de materia prima, también señalaban a la descapitalización y falta de modernización de empresas como elementos a destacar, por lo cual se movían junto con los empresarios para solicitar créditos en diferentes bancos. En el caso de Bunge y Born, sobre fines de 1968, se la mencionaba como una de las empresas que realizaba inversiones. ${ }^{46}$ Es que los Congresos anteriores -al menos desde 1967- mostraban la crisis por la que atravesaban fábricas aceiteras de diferentes provincias. La falta de materias primas, las suspensiones, las compensaciones mediante bonificaciones o préstamos eran debatidas ante la situación de empresas de las provincias de Entre Ríos y Santa Fe. Se denunciaba también los "traslados" de obreros entre fábricas, y la crisis con cierre de plantas en Bahía Blanca, Córdoba, Misiones y Formosa. ${ }^{47}$ Una especial preocupación aparecía en relación a

\footnotetext{
${ }^{43}$ Ministerio de Gobierno Provincia de Santa Fe, Informe, Santa Fe, 8 de febrero de 1972. (APMSF).

${ }^{44}$ El Petroquimico, núm. 16, marzo/abril de 1972, citado en Ceruti, Leónidas y Resels, Mariano, Democracia directa..., op. cit., pp. 248-252.

45 Avanzada Socialista, "Intersindical de San Lorenzo. Otra vez en lucha", año 1, núm. 5, 29 de marzo de 1972. (ADFP).

46 Actas del Congreso Federación Obrera de la Industria Aceitera y afines FOLAA, noviembre de 1972 y noviembre de 1970, noviembre de 1968, citado en Ceruti, Leónidas Noni, Aceiteros y desmotadores. Hacemos historia. 70 años $1947-$ 2017, Ediciones del Castillo, Rosario, 2000; tomo I, p.161, p. 151 y p.131.

${ }^{47}$ Actas del Congreso FOIAA, noviembre de 1969, citado en Ceruti, Leónidas Noni, Aceiteros y desmotadores..., op. cit. pp. 139 a 144.
} 
las tres fábricas de la ciudad de Esperanza, en la provincia de Santa Fe, que también formaba parte de las inquietudes del Servicio de Informaciones provincial. ${ }^{48}$

Según se aprecia en las actas de la Federación Nacional, el escenario se agravó en el año 1971 y 1972 en diferentes provincias. En Santa Fe, la situación era calificada como grave. En Esperanza las tres fábricas permanecían paradas y había sido convocado un paro total de actividades. Esto a pesar de la "buena relación" que el Secretario General de la Federación ostentaba sostener con el gobernador de Santa Fe, General Sánchez Almeyra y su amistad con su Ministro de Agricultura. El año de 1972 se cerraba así con suspensiones, despidos, incertidumbre y falta de cobro de indemnizaciones por parte de los trabajadores, el gremio realizando gestiones y las empresas acudiendo al pedido de créditos. Según los datos manejados por la Federación, el 60\% de las empresas estaban paralizadas. ${ }^{49}$

En la región, en particular, según la información policial, el cordón industrial norte, es decir, la zona comprendida entre Granadero Baigorria a Puerto General San Martín, concentraba trece sindicatos e integraba 10.000 trabajadores aproximadamente..$^{50}$

En cuanto al panorama sindical aceitero nacional, era muy heterogéneo. La Federación estaba alineada con la CGT Azopardo, en tanto los gremios locales de la rama asumían diferentes posturas asociadas a la heterogeneidad del movimiento sindical de la región y del gremio aceitero en particular.

En la ciudad de Rosario funcionaba el Sindicato de Obreros y Empleados Aceiteros y Afines desde 1951, que había sido fundado sobre la base de la Asociación de Obreros "Santa Clara" y al que se integraron otros sindicatos de la región. Dicha organización se integró a la Federación Aceitera, compuesta además por otros sindicatos aceiteros de diversas provincias. El pequeño Sindicato de San Lorenzo, por su parte, poseía poco más de 300 afiliados pertenecientes a la fábrica Molinos Río de la Plata, integrante del grupo Bunge y Born. Protagonista central del conflicto de 1972, integraba la CGT y la citada Intersindical de Gremios de San Lorenzo, junto con otros como SOEPU, Sindicato de Químicos Papeleros, Químicos de San Lorenzo, Ceramistas, Comisión Interna de Sulfacid y distintas agrupaciones de base, es decir, estaba enrolado en los gremios clasistas y combativos del cordón norte del Gran Rosario. No formaban parte de la Intersindical los gremios de la construcción, metalúrgicos, petroleros y los de las fábricas Delta e INDO de Puerto San Martín.

Justamente el Sindicato aceitero de Puerto San Martín, agrupaba a los trabajadores de INDO. ${ }^{51}$ Estaba adherido a la CGT, pero no a la Intersindical. Fue intervenido y un trabajador "sindicado como de ideología comunista" fue despedido, ante lo cual esta última tomó en sus manos la demanda de reincorporación y llamó a un paro regional. La medida de fuerza fue convocada por diversos reclamos: la "normalización del gremio de INDO, sin injerencia patronal ni gubernamental, costo de vida, aumento de emergencia, nuevas escalas salariales, reincorporación de los cesantes de los últimos 5 años, edad jubilatoria de 55 años y derogación de la ley de alquileres". ${ }^{2}$ Dicho paro -según un informe de inteligencia- no había contado con gran acatamiento, y se había sostenido gracias a la presencia de estudiantes y activistas de Rosario y

\footnotetext{
48 Actas del Congreso FOIAA, noviembre de 1969..., op. cit.; Policía de la Provincia de Santa Fe, Servicio de Inteligencia y Comunicaciones, "Memorandum", Santa Fe, núm. 1402, 7 de octubre de 1970. (APMSF)

${ }^{49}$ Memoria y balance 1970/71, p.151 y Actas Congreso noviembre de 1972, citado en Ceruti, Leónidas Noni, Aceiteros y desmotadores..., op. cit. pp. 157 y 158.

${ }^{50}$ Gobernación de Santa Fe. Central de Inteligencia. Informe especial de inteligencia, №18, 10 de noviembre de 1971. (APMSF).

${ }^{51}$ Ceruti, Leónidas Noni, Aceiteros y demotadores..., op. cit.

${ }^{52}$ Director General de Informaciones de la Provincia al Jefe de la Central de Inteligencia, Memorandum, Santa Fe, 29 de julio de 1971. (APMSF).
} 
Córdoba, evidenciado en "los domicilios y calidad de los setenta y tres detenidos en la emergencia". ${ }^{53}$

Los rumores de cierre de Molinos comenzaron ya a principios de 1971, anunciando la cesantía de alrededor de 300 trabajadores. Por ello, la Intersindical incorporó dentro de un conjunto de reclamos, la demanda de evitar el cierre y traslado de la planta. ${ }^{54} \mathrm{Ya}$ el 24 de marzo de ese año realizaron un paro de dos horas en apoyo a los trabajadores cordobeses tras el "Viborazo" y contra el cierre.

Según el informe de inteligencia, ese paro fue acatado por la totalidad de los trabajadores de Cerámica Verbano, SADE, Cerámica Río Paraná, la mitad de los trabajadores de Cerámica San Lorenzo y Petroquímica de Puerto General San Martín, casi la mitad de Celulosa, más de la mitad de Duperial y de Electroclor, casi la totalidad de Sulfacid y el comercio de San Lorenzo. En el caso de Molinos, sobre 345 trabajadores, lo habían hecho 180. Según la misma fuente, los adherentes al paro totalizaban 2965, mientras una cantidad levemente superior, que ascendía a 3060 empleados y obreros, no había adherido: construcción de San Lorenzo, INDO, Delta y portuarios de Puerto General San Martín, Junta Nacional de Granos, Municipales, Banco Provincial de Santa Fe, Internacional y Nación, correo, un taller metalúrgico y SUPE San Lorenzo. Si bien estas cifras exhiben un $50 \%$ de acatamiento en general y algunas fábricas totalmente paradas, el informe lo consideraba "intrascendente". 55

La demanda contra los despidos pasó a ocupar un papel destacado. Estuvo en el centro de la reunión del 2 de abril de 1971, donde concurrieron aproximadamente 100 personas, "las que en su mayoría eran ex obreros y empleados despedidos en los últimos años por los establecimientos de la zona". Entre sus resoluciones se planteó la posibilidad de convocar a un paro general frente a nuevos despidos (como los de Jabón Kopp) o el cierre de Molinos.

Una de las acciones más resonantes de la Intersindical fue la convocatoria a la Asamblea Obrero Popular, con paro, que fue autorizada -mediante un artilugio legal- no a la Intersindical, sino a gremios adheridos a la CGT, como los aceiteros de San Lorenzo y los Químicos Papeleros de Capitán Bermúdez, que poseían la personería necesaria para obtener el permiso. Dicha asamblea se realizó el día 29 de julio de 1971, con la asistencia de 110 delegados. Se realizó con un fuerte operativo policial, el cual fue denunciado durante el transcurso de la asamblea y que culminó con cerca de cien detenciones, incluidos dirigentes del sindicalismo cordobés. ${ }^{56}$

La Federación Aceitera, por su parte, se había opuesto a la realización de una reunión previa en Puerto General San Martín, exhibiendo su disconformidad con la autorización otorgada por el gobierno provincial a los trabajadores de INDO, "con [la] finalidad [de] disponer paros [de] tareas y cuyo permiso es solicitado por obreros ajenos al gremio desconociendo así [la] autoridad [del] delegado electoral designado por [el] Ministerio de Trabajo de la Nación." Y solicitaban intervención para "terminar con amenazas contra trabajadores que desean tranquilidad ya que en caso de continuar [el] apoyo de autoridades [de] esa provincia a actos como los que suceden en Puerto General San Martín obligará a esta Federación a disponer medidas de fuerza [de los] trabajadores aceiteros de la Provincia...". ${ }^{57} \mathrm{Al}$ año siguiente, algunas voces que se alzaron durante el transcurso del Congreso anual, mostraban la aparición de direcciones de filiales opositoras, como en Misiones, donde un congresal denunció "elementos que conspiran contra esta organización, con

\footnotetext{
53 Gobernación de Santa Fe. Central de Inteligencia, Informe especial de inteligencia, N¹8, op. cit.

${ }^{54}$ Gobernación de Santa Fe. Central de Inteligencia, Informe especial de inteligencia Nº1, 4 de agosto de 1971. (APMSF).

${ }^{55}$ Gobernación de Santa Fe. Central de Inteligencia, Informe especial de inteligencia $\mathrm{N}^{\circ} 01$, op. cit.

${ }^{56}$ Gobernación de Santa Fe. Central de Inteligencia, Informe especial de inteligencia $\mathrm{N}^{\circ}$ 01, op. cit.; Dowling, Juan Alfonso, "Petroquímicos, la intersindical y la democracia. Una experiencia de lucha de los trabajadores en la zona industrial de San Lorenzo", en AAVV, Nuevas tendencias en el sindicalismo: Argentina-Brasil, Biblos, Buenos Aires, 1992, pp. 113-133.

${ }^{57}$ Gobernación de Santa Fe. Central de Inteligencia, Informe especial de inteligencia Nº1, op. cit.
} 
fines político partidarios", en especial mediante la actuación de las Ligas Agrarias, manejada por "los zurdos, en este momento lo está por los curas del Tercer Mundo y los comunistas...", así como al menos un "trotskista metido a peronista...". 58

$\mathrm{El}$ informe de inteligencia vaticinaba un verdadero y grave frente de conflicto, "una verdadera convulsión" de producirse los 300 despidos de Molinos, al colocarlos "ante dos alternativas: a) quedarse sin ocupación o empleo; b) trasladarse a la ciudad de Avellaneda o a sus alrededores, donde su caótica situación económica se vería agravada a raíz del alto costo de los alquileres". Las conclusiones del informe apuntaban a la pretensión de los dirigentes de la Intersindical de "constituirla en una base izquierdista para entablar una lucha violenta contra la conducción gubernamental y constituir la zona industrial de San Lorenzo en "área crítica" similar al conglomerado industrial cordobés". ${ }^{99}$ Poco después volvían sobre el particular, al señalar directamente la intervención del clasismo cordobés de SITRAC-SITRAM, la "subversión encubierta en el gremialismo revolucionario (Agrupaciones $1^{\circ}$ de mayo)" que podría desplazar "el centro de gravedad a otras áreas donde exista alta concentración industrial y conflictos gremiales a nivel manifiesto y/o latente", como el caso del cordón industrial del Gran Rosario, donde más que conflictos existentes, veían concentración industrial y "proximidad a una base estudiantil y guerrillera activa" en Rosario, y temían "intentos de aprovechamiento". ${ }^{0}$

Llamativamente, el Jefe de Inteligencia aconsejaba "digitar" el apoyo a la CGT Rosario y tener presente que el peronismo "ha frenado y frena" la penetración de extrema izquierda. Es más, elogiaban la capacidad de la CGT Rosario por su "apreciable contralor" de los problemas existentes en la zona. ${ }^{61}$

Pocos meses después, el conflicto había estallado. Lo que se manejaba como posibilidad en 1971 se hacía realidad a principios del año siguiente. La empresa ofreció transferir personal a la fábrica de Avellaneda o a otras empresas del grupo Bunge y Born; para quienes no aceptaran el traslado, abonarían indemnización completa y dos meses de preaviso; para todo un conjunto de trabajadores próximos a jubilarse, pagarían indemnizaciones especiales; ofrecían además salidas alternativas como conceder trabajos de mantenimiento y provisión de piezas para quienes aceptaran trabajar como contratistas o créditos para adquirir maquinarias, herramientas y equipos del establecimiento a cerrarse. ${ }^{62}$

Hacia principios del año 1972 la Intersindical y el Sindicato intensificaron las acciones, como la asamblea reunida en el local de aceiteros el 30 de enero por la mañana, con la asistencia de 200 personas aproximadamente, que facultó a la directiva a realizar todas las gestiones necesarias, en conjunto con la Intersindical. Se propusieron paros escalonados, de una hora el 24 de marzo, dos horas el 27, y tres horas el 29, por turno y con asambleas de fábrica, que fue acatado en su totalidad con excepción del último en Cerámica San Lorenzo. ${ }^{63} \mathrm{Al}$ movimiento contra el cierre se sumaron comerciantes e industriales locales, que veían un futuro incierto ante la imposibilidad de absorción de los despedidos en nuevos puestos de trabajo. También las autoridades diagnosticaban que no habría reabsorción de trabajadores en otras fábricas, tampoco nuevas radicaciones y las fábricas existentes se encontraban en proceso de automatización. ${ }^{64}$

\footnotetext{
58 Actas del Congreso FOIAA, noviembre de 1972, citado en Ceruti, Leónidas Noni, Aceiteros y desmotadores..., op. cit. pp. 159.

${ }^{59}$ Gobernación de Santa Fe. Central de Inteligencia, Informe especial de inteligencia No01, op. cit.

${ }^{60}$ Gobernación de Santa Fe. Central de Inteligencia. Informe especial de inteligencia, $\mathrm{N}^{\circ} 18$, op. cit.

${ }^{61}$ Gobernación de Santa Fe. Central de Inteligencia, Informe especial de inteligencia $\mathrm{N}^{\circ} 01$ y Nº18, op. cit.

${ }^{62}$ Ministerio de Gobierno Provincia de Santa Fe, Informe, Santa Fe, 8 de febrero de 1972, op. cit.

63 Avanzada Socialista, "Intersindical de San Lorenzo, otra vez en Lucha", año 1, núm. 5, 29 de marzo de 1972. (ADFP); El Petroquímico, "El cierre de Molinos", núm.16, marzo/abril de 1972, citado en Ceruti, Leónidas y Mariano Resels, Democracia directa..., op. cit, p. 248-252.

${ }^{64}$ Policía de la Provincia de Santa Fe. Jefatura del Departamento San Lorenzo, Informe al Jefe de la Unidad Regional V de la Policía de Santa Fe, 2 de febrero de 1972. (APMSF).
} 
Sin embargo, según la postura de diversos actores, faltó un plan de lucha de conjunto, dejando las gestiones en manos del Sindicato, que acudió a la CGT. ${ }^{65}$ Algunos opinaban sobre la necesidad de profundizar la lucha extendiéndola a Rosario y denunciaron la demora de la CGT Rosario en actuar. ${ }^{66}$ Otros cuestionaron los paros parciales y la falta de "consignas de acción directa y de movilización de masas". ${ }^{67}$ Las posturas en cuanto a las soluciones entre los trabajadores y las corrientes políticas tampoco eran homogéneas: si todos acordaban en la lucha contra el cierre, variaron sus posturas entre la nacionalización y la cooperativa mixta. ${ }^{68}$

El accionar de la empresa, además de las "mentiras y promesas" ${ }^{69}$ incluyó el ofrecimiento de "elevadas sumas de dinero a los dirigentes gremiales", y "un "movimiento de ablande" a nivel de dirigentes para lograr solución al problema". ${ }^{70}$

Sin embargo, la preocupación de la Policía y la Central de Inteligencia crecía "debido al provecho que del mismo pueden sacar los sectores extremistas, interesados en aprovechar toda oportunidad para provocar la agitación social". Señalaban: "Esta acción sin duda será capitalizada por los grupos activistas subversivos que, si bien hasta la fecha han mantenido una actitud pasiva en la zona, es innegable su existencia y por descartado (sic) su inmediata injerencia en este problema con su secuela de atentados, acciones guerrilleras, etc." y mencionaban explícitamente a las "FAL, FAP o ERP" ${ }^{71}$

Llamativamente, señalaban el accionar de la Intersindical en el marco de los gremios clasistas y combativos, en PASA, Verbano, INDO, Celulosa y Electroclor como sitios donde ganaban batallas, en sus términos "en cada planteo obrero-patronal han triunfado en sus reclamaciones" ... y cuentan con posibilidades ciertas de éxito". Más que batallas por reivindicaciones económicas, veían allí triunfos políticos. ${ }^{72}$

Lo cierto es que las organizaciones de izquierda prestaron atención a la situación planteada alrededor del conflicto. También el ERP participó al menos en la asamblea de aceiteros San Lorenzo del 31 de marzo, "llevando su apoyo a los trabajadores en conflicto". 73 Según algunos testimonios, la experiencia de Molinos significaría para el PRT-ERP "una profundización de la experiencia en fábrica... además de ampliar la zona de inserción". ${ }^{74}$

El 4 de abril, la prensa informaba que, sobre 260 trabajadores, 80 habían aceptado las indemnizaciones y 40 quedarían trabajando en la planta que se utilizaría como depósito de semillas. ${ }^{75} \mathrm{El} 8$ de abril en asamblea con la presencia de miembros de la Intersindical, "los obreros aceiteros decidieron el cobro de la indemnización y el abandono de la lucha". ${ }^{76}$ Hacia mediados de

${ }^{65}$ El Petroquímico, "El cierre de Molinos", núm.16, marzo/abril de 1972, citado en Ceruti, Leónidas y Mariano Resels, Democracia directa..., op. cit, p. 248-252-.

${ }^{66}$ Avanzada socialista, "Intersindical de San Lorenzo, parar el cierre", núm. 6, 5 de abril de 1972, p. 5. (ADFP).

67 Política Obrera, "No a la tregua: los sindicatos de San Lorenzo luchan!", 1 de abril 1972, p. 4. (Marxists Internet Archive), disponible en: https://www.marxists.org/.

${ }^{68}$ Avanz̧ada Socialista, "Intersindical de San Lorenzo. Otra vez en lucha", año 1, núm. 5, 29 de marzo de 1972. (ADFP).

${ }^{69}$ El Petroquímico, "El cierre de Molinos", op. cit.

70 Dirección General de Informaciones de la Provincia Delegación Rosario, Memorandum elevado a la Dirección General de Informaciones de la Provincia, 14 de marzo de 1972. (APMSF).

${ }^{71}$ Nota del Jefe de Policía de la Provincia de Santa Fe al Señor Ministro de Gobierno, 8 de febrero de 1972. (APMSF) y Policía de la Provincia de Santa Fe. Jefatura del Departamento San Lorenzo al Sr. Jefe de la Unidad Regional V, Panorama Gremial, 2 de febrero de 1972. (APMSF). El documento refiere, además de al citado ERP, a otras dos organizaciones político militares: FAL -Fuerzas Argentinas de Liberación- y FAP -Fuerzas Armadas Peronistas-.

72 Policía de la Provincia de Santa Fe. Jefatura del Departamento San Lorenzo al Sr. Jefe de la Unidad Regional V, op. cit.

${ }^{73}$ Estrella Roja, núm.12, abril de 1972, p.14 (ARD); Scoppetta Laura y Torres, Pablo "La apuesta armada..., op. cit.

74 Pasquali, Laura, "Éramos jóvenes...", op. cit. p. 30.

${ }^{75}$ El Litoral, Santa Fe, 4 de abril de 1972. (Archivo de la Provincia de Santa Fe- Hemeroteca Digital), disponible en: http://www.santafe.gov.ar/hemerotecadigital/articulo/ellitoral/. Las versiones sobre la cantidad de despidos oscilan entre 260 y 350 trabajadores.

${ }^{76}$ El Petroquímico, "El cierre de Molinos", op. cit. 
abril ya se denunciaban atentados represivos contra activistas y locales partidarios, con maltratos y golpes para que "confesaran sus relaciones con el ERP”. Los responsables eran integrantes de "fuerzas combinadas de la Policía Provincial y del Ejército, entre las cuales se encontraba el Jefe de Policía, Comandante Feced". Esta escalada represiva fue acrecentada tras el asesinato del Comandante del Segundo Cuerpo de Ejército General Sánchez, por parte de un comando conjunto del ERP y las FAR. ${ }^{77}$

Tras este duro conflicto, que concitó una amplia solidaridad pero también la "traición" de "algunos aceiteros y de la CGT", "comenzó el debilitamiento y la extinción" de la Intersindical. ${ }^{78}$ La firme negativa de los principales dirigentes del sindicato a cobrar 15 millones de pesos $\mathrm{m} / \mathrm{n}$, contrasta con un caso que derivó en la expulsión de un integrante de la directiva que se habría avenido a cobrar la suma de 5 millones de pesos, tras lo cual fue expulsado por "traidor". ${ }^{79}$ Según algunos testimonios, como el de un integrante de la organización Montoneros Sabino Navarro, para mediados de 1973 el sindicato aceitero estaba vaciado, era un sindicato fantasma ${ }^{80}$ Es que el traslado significó el despido de trescientos trabajadores y el vaciamiento de uno de los sindicatos combativos, integrante de la Intersindical, que según los organismos de inteligencia contaba con 321 afiliados y era uno de los más activos en su interior. ${ }^{81}$ Sin embargo, en el boletín del SOEPU se leía: "los obreros que luchamos y pedimos salarios, no podemos dejar de estar orgullosos de la solidaridad brindada". ${ }^{82}$

\section{Consideraciones Finales}

En este trabajo hemos abordado el análisis de las batallas libradas por dos colectivos obreros pertenecientes a ramas escasamente abordadas, más bien excluidas del análisis en la indagación sobre los procesos de radicalización social y política que sucedieron al "Cordobazo" y los "Rosariazos". Hemos buscado las claves del accionar obrero y sindical en las condiciones estructurales atravesadas por ambas ramas de la alimentación: frigorífica y aceitera y en las particulares condiciones creadas por los realineamientos, conflictos y tensiones gremiales nacionales y regionales.

En el caso de la industria frigorífica, hemos mostrado que a pesar del férreo control ejercido por un sector del peronismo tradicional y de los rasgos constitutivos del colectivo obrero en términos de calificación, salario y formación técnica, diversas vertientes de la izquierda armada y no armada buscaron y lograron diferentes grados de inserción tanto en los muros de la fábrica como fuera de ella, en las barriadas obreras.

Para los aceiteros, situados en un espacio donde la historiografía colocó el foco de análisis y aun formando parte de la vertiente más radicalizada de organización sindical de la región en su conjunto -la Intersindical-, la batalla se sostuvo mientras la solidaridad en la región lo posibilitó, sin extenderse al conjunto de la región y sin lograr persuadir a los trabajadores del significado del cobro de las indemnizaciones.

Un elemento significativo que marcó el pulso de las batallas libradas durante estos años por los obreros de los frigoríficos y las aceiteras del Gran Rosario fue el carácter defensivo de los conflictos, en defensa de los puestos de trabajo frente a los procesos de reconversión que comenzaban a

\footnotetext{
77 Avanzada Socialista, "En Rosario y Tucumán: Socialistas perseguidos”, núm.8, 19 de abril de 1972, p. 3. (ADFP).

${ }^{78}$ Ceruti, Leónidas y Mariano Resels, Democracia directa..., op. cit., p. 152.

79 Dirección General de Informaciones de la Provincia Delegación Rosario, Memorandum elevado a la Dirección General de Informaciones de la Provincia, 14 de marzo de 1972, op. cit.

${ }^{80}$ Seminara, Luciana, Bajo la sombra del ombú. Montoneros Sabino Navarro, historia de una disidencia, Buenos Aires, Imago Mundi, 2015, p.55. Se trata de una organización político militar que surgió como disidencia de Montoneros, con peso en Rosario y Córdoba.

${ }^{81}$ Gobernación de Santa Fe. Central de Inteligencia, Informe especial de inteligencia No01, op. cit.

82 El Petroquímico, "El cierre de Molinos", op. cit.
} 
desplegarse en ambas industrias. En tal sentido, fue posible identificar que las luchas obreras se caracterizaron por los intentos realizados en articular la conflictividad laboral con otros gremios y actores presentes en los espacios barriales y urbanos. 